\title{
openheart Incident hypertension in urban slums of central India: a prospective cohort study
}

\author{
Abhijit P Pakhare (10 , ${ }^{1}$ Anuja Lahiri, ${ }^{1}$ Neelesh Shrivastava (10 , ${ }^{2}$ Ankur Joshi, ${ }^{1}$ \\ Sagar Khadanga, ${ }^{3}$ Rajnish Joshi (1) ${ }^{3}$
}

To cite: Pakhare AP, Lahiri A, Shrivastava N, et al. Incident hypertension in urban slums of central India: a prospective cohort study. Open Heart 2021;8:e001539. doi:10.1136/ openhrt-2020-001539

Received 1 December 2020 Revised 4 January 2021 Accepted 6 January 2021
A) Check for updates

C) Author(s) (or their employer(s)) 2021. Re-use permitted under CC BY-NC. No commercial re-use. See rights and permissions. Published by BMJ.

${ }^{1}$ Community and Family Medicine, All India Institute of Medical Science, Bhopal, Madhya Pradesh, India ${ }^{2}$ NCD Urban Project, All India Institute of Medical Science, Bhopal, Madhya Pradesh, India ${ }^{3}$ General Medicine, All India Institute of Medical Science, Bhopal, Madhya Pradesh, India

Correspondence to Dr Rajnish Joshi; rajnish. genmed@aiimsbhopal.edu.in

\section{ABSTRACT}

Background Numerous studies have highlighted the burden of hypertension by estimating its prevalence. However, information regarding quantum and characteristics of persons whose blood pressure converts to hypertension range from their previous state of prehypertension or normal blood pressure is crucial for any public health programme. We aimed to estimate incidence rate of hypertension and to identify risk factors for the same, so that it is useful for programme implementation.

Methods We established a cohort of adults residing in urban slums of Bhopal, who were registered in a baseline cardiovascular risk assessment survey, which was performed between November 2017 and March 2018. Blood pressure assessment was done at least three times at baseline for diagnosis of hypertension, which was defined as systolic blood pressure $\geq 140 \mathrm{~mm} \mathrm{Hg}$ or diastolic blood pressure $\geq 90 \mathrm{~mm} \mathrm{Hg}$ on two occasions. Participants who did not have a diagnosis of hypertension were followed up during April-June 2019.

Results Of the 5673 participants assessed at baseline, 4185 did not have hypertension of which 3199 (76.4\%) were followed up after a median on 1.25 years (IQR $1.08-1.60)$ and a total of $170(5.31 \%)$ individuals were detected with incident hypertension. Overall incidence rate of hypertension was $4.1(95 \% \mathrm{Cl} 3.54$ to 4.75$)$ per 100 person-years of follow-up. On multivariate analysis, age (relative risk/RR 1.98; $95 \% \mathrm{Cl} 1.19$ to 3.3, for age $>60$ years), being in first and second wealth tertile (T-1 RR 1.85; 95\% Cl 1.17 to 2.91) and being illiterate (RR 1.94; 95\% Cl 1.31 to 2.86) were significant predictors of incident hypertension. Individuals who had prehypertension at baseline also had a significantly increased risk of developing hypertension (RR 2.72; 95\% Cl 1.83 to 4.03 )

Conclusions We found that incidence of hypertension in urban slums of central India is higher with increasing age and in men. Illiteracy, lower Wealth Index and prehypertension are other determinants. We also demonstrate feasibility of establishing a cohort within the public health delivery system, driven by efforts of community health workers.

\section{INTRODUCTION}

Hypertension is a leading cause of cardiovascular diseases (CVDs) globally and in India. About one-third of all urban and one-fourth of all rural adults in India have hypertension. ${ }^{1}$

\section{Key questions}

What is already known about this subject?

- While prevalence of hypertension in adults is high and is increasing over time, estimates about incidence of hypertension from low/middle-income countries are limited. Previous estimates from India have ranged from $3.3 \%$ to $8.2 \%$.

What does this study add?

- This study provides estimates of incidence of hypertension and also identifies vulnerable groups within the urban slum population, who are more at risk.

How might this impact on clinical practice?

- Hypertension, being a lifelong condition, is not likely to change its prevalence in short term. Reduction in annual incidence can be an achievable aim and will help programme managers to evaluate benefit.

- Robust incidence rates will improve planning for scale up of hypertension control services in the community.

Previous studies by our group have estimated prevalence of hypertension and its risk factors in state-wide representative survey of Madhya Pradesh. We found that prevalence to be $25.7 \%$ in urban and $20.8 \%$ in rural areas. ${ }^{2}$ These numbers translate into more than 200 million individuals with hypertension in India. ${ }^{3}$ Given this huge burden, National Program for Cancer, Diabetes, Cardiovascular diseases and Stroke (NPCDCS) launched by the government of India envisages annual screening for hypertension in all adults above 30 years of age. ${ }^{4}$ Once such screening is fully operationalised, individuals with newly detected hypertension are likely to add on to the overall burden. There are only a limited studies on incidence of hypertension from India. In a previous cohort of 300 individuals (age range 15-64 years) from southern Indian state of Kerala, India, nearly one-fourth individuals developed hypertension in 7 years of follow-up from 2003 to $2010 .^{5}$ This $3.3 \%$ annual incidence was the only community-based benchmark from India, until publication of a multicity CARRS 
Study (Chennai, New Delhi and Karachi) in 2017 among adults with age 20 years or more, provided an annual incidence estimate of $8.2 \% .{ }^{6}$ A recently published cohort from eastern state of West Bengal has reported incidence of hypertension among adults of age 18 years or more to be $5.9 \%$ for women and $7.9 \%$ for men, respectively. ${ }^{7}$

Rise in incidence has led to increase in prevalence of hypertension and bridging of rural-urban gap. ${ }^{8}$ In addition to incidence, increased survival and thereby duration of disease can also be attributed to rise in prevalence. It is important to identify risk factors of such incident hypertension beyond age, in case the tide needs to be stemmed. Previous studies have identified elevated blood pressure (previously known as prehypertension) as a key risk factor, which simply indicates a transition from a normal to hypertensive state. ${ }^{56}$ Obesity, smoking, alcohol use and dysglycaemia are other reported significant factors in these two studies from India. Lack of physical activity and increase in alcohol use have been identified as key risk factors in two recent meta-analyses. ${ }^{9} 10$ The evidence base of incident hypertension and its risk factors is sparse and there is a need to better understand relationships in cohort studies, especially in vulnerable population subgroups.

Two-thirds of population of India is young, and more than half of all adults residing in urban areas are economically disadvantaged. ${ }^{11}$ These population subgroups are most vulnerable to develop incident hypertension, contributing to overall CVD burden. The current study is designed to estimate incidence of hypertension and its predictors on follow-up. In addition to project future anticipated burden of disease and identification of vulnerable groups, incidence information is also important to assess operational adequacy of NPCDCS in the envisaged annual follow-up surveys.

\section{METHODS}

\section{Design}

We established a cohort of adults residing in urban slums of Bhopal to estimate incidence of hypertension. Detailed methods of the study are described in a preprint of manuscript under publication and are available on preprint server. ${ }^{12}$

\section{Setting}

We identified a total of 16 urban slum clusters in Bhopal, a city located in central India. Accredited social health workers (ASHAs), one from each cluster was trained to perform CVD risk assessment, follow-up of the participants and to improve their linkages with public health system. They were supported by a team of study physicians and supervisors, for hand-holding and confirmation of hypertension status.

\section{Participants}

All adults residing in these areas were invited for participation in a baseline cardiovascular risk assessment survey, which was performed between November 2017 and March
2018. The primary purpose of the baseline survey was to identify individuals at higher CVD risk (hypertension, diabetes mellitus) and improve their linkages to primary care facilities. Blood pressure assessment was done at least three times at baseline for diagnosis of hypertension, which was defined as systolic blood pressure (SBP) $\geq 140 \mathrm{~mm} \mathrm{Hg}$ or diastolic blood pressure (DBP) $\geq 90 \mathrm{~mm}$ $\mathrm{Hg}$ on two or more occasions.

All the participants of baseline survey, who did not have a diagnosis of hypertension, were invited for follow-up. Individuals who were pregnant or those who refused for a follow-up assessment were excluded. There were no other exclusions. Follow-up survey was performed between April and June 2019.

\section{Procedures}

Both baseline and follow-up measurement of blood pressure was performed using the same methodology. We measured blood pressure using a digital sphygmomanometer (Omron digital apparatus, model 7200, Kyoto, Japan) with standard-sized adult cuff. All measurements were done with participants in a sitting position, with well-supported arm and back. An average of three readings obtained $1 \mathrm{~min}$ apart was recorded as blood pressure at that time. These measurements were obtained at home by ASHAs. Blood pressure was verified for all individuals who had values for $\mathrm{SBP} \geq 140 \mathrm{~mm} \mathrm{Hg}$ or $\mathrm{DBP} \geq 90 \mathrm{~mm} \mathrm{Hg}$, and for $10 \%$ of all other individuals by a trained supervisor. All individuals who had elevated blood pressure had their status verified by a study physician at a primary care facility, before classifying them as having newly diagnosed hypertension.

\section{Statistical analysis}

Baseline data were collected on mobile phone-based application (CommcareHQ), it was then exported in Excel and then cleaned and analysed in $\mathrm{R}$ software. ${ }^{13}$ Information on baseline variables (age, gender, education, wealth quintiles, smoking status, alcohol consumption, physical activity level, body mass index (BMI), waist circumference, glycaemic status) was abstracted from this dataset. All individuals who did not have a diagnosis of hypertension at baseline, but had their SBP between 120 and 139 or diastolic BP between 80 and 89 were classified as having elevated blood pressure (or prehypertension). All individuals who had their random blood sugar values of $140 \mathrm{mg} / \mathrm{dL}$ or greater at baseline were classified as having dysglycaemia. Incidence rate of hypertension and its CI were estimated by using binom ${ }^{14}$ package in $\mathrm{R}$ software which uses binomial distribution. It is expressed as incidence per 100 person-years of follow-up. The gtsummary ${ }^{15}$ package in $\mathrm{R}$ software was used to create summary table grouped by presence or absence of incident hypertension. Comparison of distribution of sociodemographic and clinical factors among those who developed incident hypertension and those who did not was done by using $\mathrm{X}^{2}$ or t-test appropriately. Development of incident hypertension in a given time is a binary variable. 


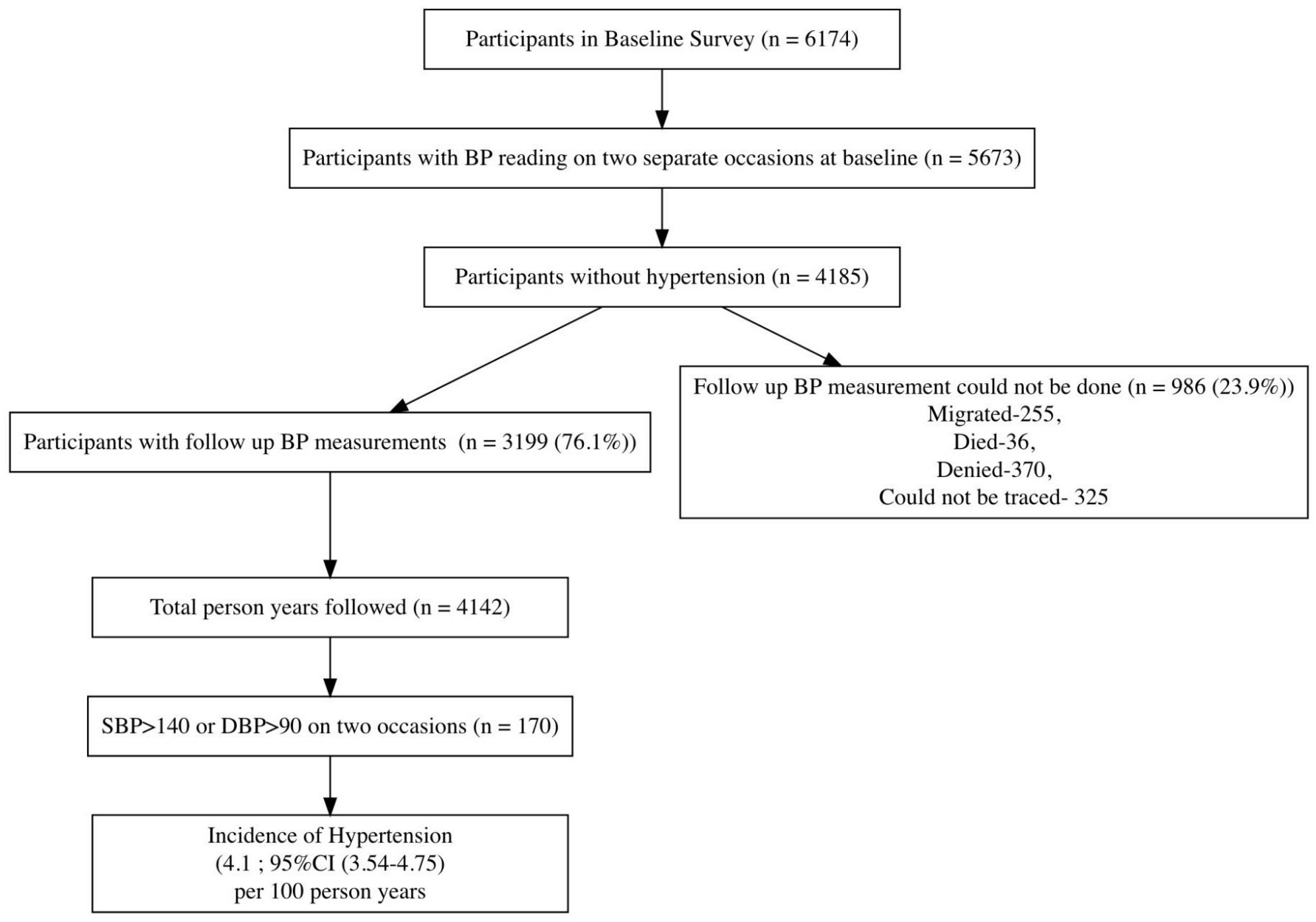

Figure 1 Study flow chart. BP, blood pressure; DBP, diastolic blood pressure; SBP, systolic blood pressure.

To identify the independent predictors of developing incident hypertension, we have performed relative risk (RR) regression by using maximum likelihood regression for log-binomial models; logbin ${ }^{16}$ package in R software was used for this purpose. The logbin package provides different algorithms for fitting log-link binomial generalised linear model (RR regression), allowing stable maximum likelihood estimation and obeying parameter constraints. ${ }^{16}$ We first entered sociodemographic and clinical variables individually to estimate RR and CI while adjusting for follow-up time. Then we have selected variables with $\mathrm{p}<0.20$ for entering in to RR regression model. We have used 'CEM 'algorithm and 'squarem' method for acceleration in logbin package. Then adjusted RR and its $\mathrm{CI}$ are presented in results.

\section{RESULTS}

Of the 6174 participants approached at baseline, two blood pressure readings on separate occasions were available for 5673 participants. Out of these, 4185 participants did not have hypertension at baseline and were considered as cohort base. Of these, 3199 (76.4\%) were followed up after a median on 1.25 years (IQR 1.08-1.60) (figure 1). Among this cohort of 3199 individuals, most were below 45 years of age $(2013 ; 62.9 \%)$, were women (1937; 60.5\%), had a BMI below $25 \mathrm{~kg} / \mathrm{m}^{2}$ $(1708 ; 53.4 \%)$ and were classified as sedentary $(2373$; $74.2 \%$ ) based on leisure time physical activity levels (table 1). Online supplemental table 1 shows comparison of baseline characteristics among those who were followed and who were lost to follow-up. Relatively more men, those belonging to lower wealth quintile, having low BMI and low waist circumference, a non-sedentary lifestyle, tobacco users and alcohol users were more likely to be lost to follow-up.

A total of 170 individuals $(5.31 \%)$ were detected with a new onset hypertension. New onset hypertension was confirmed only after repeat measurements by the study supervisor and study physician, thus verifying all the elevated blood pressure values obtained by ASHAs. Overall incidence of hypertension was 4.1 (95\% CI 3.54 to 4.75$)$ per 100 person-years of follow-up. Incidence was highest in those above the age of 60 years $(8.04$; $95 \%$ CI (5.38 to 11.55)) and lowest in those below 45 years of age $(2.61 ; 95 \%$ CI $(2.03$ to 3.31$))$ per 100 person-years.

On multivariate analysis, age was a significant predictor of incident hypertension (RR 1.98; 95\% CI 1.19 to 3.3, for age $>60$ years). Those belonging to first and second Wealth Index tertile were having higher risk as compared 
Table 1 Characteristics of individuals without hypertension (HTN) at baseline, stratified by HTN status on follow-up ( $n=3199)$

\begin{tabular}{|c|c|c|c|c|c|}
\hline Characteristic & $\begin{array}{l}\text { Distribution at } \\
\text { baseline } \\
\mathrm{N}=3199 / \text { person- } \\
\text { time }\end{array}$ & $\begin{array}{l}\text { No HTN on } \\
\text { follow-up } \\
\text { ( } n=3029)\end{array}$ & $\begin{array}{l}\text { Developed HTN } \\
\text { on follow-up } \\
\text { ( } n=170)\end{array}$ & $P$ value & $\begin{array}{l}\text { Incidence rate per } \\
100 \text { person-years } \\
\text { of follow-up }\end{array}$ \\
\hline Age group & & & & $<0.001$ & \\
\hline$<44$ & 2013/2637.99 & $1944(97 \%)$ & $69(3.4 \%)$ & & 2.61 (2.03 to 3.31$)$ \\
\hline $45-59$ & $900 / 1141.16$ & $828(92 \%)$ & $72(8.0 \%)$ & & 6.3 (4.9 to 7.94$)$ \\
\hline $60+$ & $286 / 360.34$ & $257(90 \%)$ & $29(10 \%)$ & & 8.04 (5.38 to 11.55$)$ \\
\hline Gender & & & & 0.003 & \\
\hline Men & $1262 / 1582.78$ & 1176 (93\%) & $86(6.8 \%)$ & & 5.43 (4.37 to 6.67$)$ \\
\hline Women & $1937 / 2556.70$ & $1853(96 \%)$ & $84(4.3 \%)$ & & 3.28 (2.62 to 4.06$)$ \\
\hline Education & & & & $<0.001$ & \\
\hline Literate & $2290 / 3003.95$ & $2194(96 \%)$ & $96(4.2 \%)$ & & 3.19 (2.58to3.90) \\
\hline Illiterate & $909 / 1135.53$ & $835(92 \%)$ & 74 (8.1\%) & & 6.51 (5.11 to 8.18 ) \\
\hline Wealth quintiles & & & & 0.007 & \\
\hline $\mathrm{T} 1$ & $847 / 1085.05$ & $791(93 \%)$ & $56(7 \%)$ & & 5.16 (3.89 to 6.70$)$ \\
\hline T2 & $986 / 1242.91$ & $929(94 \%)$ & $57(6 \%)$ & & 4.58 (3.47 to 5.94 ) \\
\hline T3 & $1216 / 1644.17$ & $1171(96 \%)$ & $45(4 \%)$ & & 2.73 (1.99 to 3.66 ) \\
\hline BMI classification & & & & 0.107 & \\
\hline$\leq 18.50$ & $308 / 394.79$ & $298(97 \%)$ & $10(3.2 \%)$ & & 2.53 (1.21 to 4.65$)$ \\
\hline $18.51-25.00$ & $1400 / 1849.40$ & 1331 (95\%) & $69(4.9 \%)$ & & 3.73 (2.90 to 4.72 ) \\
\hline $25.01-30.00$ & $663 / 895.88$ & $625(94 \%)$ & $38(5.7 \%)$ & & 4.24 (3.00 to 5.82$)$ \\
\hline $30.01+$ & $201 / 267.49$ & $185(92 \%)$ & $16(8.0 \%)$ & & 5.98 (3.41 to 9.71$)$ \\
\hline Leisure time physical activity & & & & 0.815 & \\
\hline Non-sedentary & $691 / 810.48$ & $656(95 \%)$ & $35(5.1 \%)$ & & 4.31 (3.00 to 6.00$)$ \\
\hline Sedentary & $2508 / 3329.01$ & $2373(95 \%)$ & $135(5.4 \%)$ & & 4.05 (3.40 to 4.79$)$ \\
\hline Abdominal obesity & & & & 0.180 & \\
\hline Non-obese & $1654 / 2075.44$ & $1575(95 \%)$ & $79(4.8 \%)$ & & 3.80 (3.01 to 4.74$)$ \\
\hline Obese & $1541 / 2059.87$ & $1450(94 \%)$ & $91(5.9 \%)$ & & 4.41 (3.55 to 5.42 ) \\
\hline Alcohol & & & & 0.004 & \\
\hline Non-user & $2626 / 3454.21$ & 2501 (95\%) & $125(4.8 \%)$ & & 3.61 (3.01 to 4.31 ) \\
\hline User & $573 / 685.28$ & $528(92 \%)$ & $45(7.9 \%)$ & & 6.56 (4.78 to 8.78 ) \\
\hline Tobacco & & & & 0.001 & \\
\hline Non-user & $2072 / 2751.27$ & $1982(96 \%)$ & $90(4.3 \%)$ & & 3.27 (2.63 to 4.02$)$ \\
\hline User & $1127 / 1388.22$ & $1047(93 \%)$ & $80(7.1 \%)$ & & 5.76 (4.56 to 7.17$)$ \\
\hline Current smokers & & & & 0.375 & \\
\hline Non-smokers & $3063 / 3972.67$ & $2903(95 \%)$ & $160(5.2 \%)$ & & 4.02 (3.42 to 4.70$)$ \\
\hline Smokers & $136 / 166.81$ & $126(93 \%)$ & $10(7.4 \%)$ & & 5.99 (2.87 to 11.02$)$ \\
\hline BP status 2017 & & & & $<0.001$ & \\
\hline Normal & $1836 / 2359.26$ & $1782(97 \%)$ & $54(2.9 \%)$ & & 2.28 (1.71 to 2.98 ) \\
\hline Prehypertension & $1363 / 1780.23$ & $1247(91 \%)$ & $116(8.5 \%)$ & & 6.51 (5.38 to 7.81 ) \\
\hline Dysglycaemia 2017 & & & & 0.616 & \\
\hline Absent & $2753 / 3561.98$ & $2604(95 \%)$ & $149(5.4 \%)$ & & 3.63 (2.25 to 5.55$)$ \\
\hline Present & $446 / 577.50$ & $425(95 \%)$ & $21(4.7 \%)$ & & 4.18 (3.53 to 4.91$)$ \\
\hline Follow-up years & $1.25(1.08-1.60)$ & $1.25(1.08-1.60)$ & $1.23(1.09-1.51)$ & 0.532 & \\
\hline
\end{tabular}

$\mathrm{BMI}$, body mass index; BP, blood pressure. 
Table 2 Risk of incident hypertension, univariate and multivariate relative risk $(R R)$ regression analysis $(n=3199)$

\begin{tabular}{lll}
\hline Variables & RR (univariable) & RR (multivariable) \\
\hline $\begin{array}{l}\text { Age group } \\
<44\end{array}$ & Ref & Ref \\
\hline $45-59$ & $2.33(1.69$ to $3.21, p<0.001)$ & $1.81(1.22$ to $2.67, p=0.003)$ \\
\hline $60+$ & $2.95(1.95$ to $4.48, p<0.001)$ & $1.98(1.19$ to $3.3, p=0.008)$ \\
\hline Gender & & \\
\hline Men & $1.57(1.17$ to $2.10, p=0.003)$ & $1.4(0.91$ to $2.17, p=0.126)$ \\
Women & Ref & \\
\hline Education & & - \\
\hline Literate & - & $1.9(1.35$ to $2.69, p<0.001)$ \\
\hline Illiterate & $1.94(1.44$ to $2.6, p<0.001)$ & \\
Wealth tertiles & & $1.85(1.17$ to $2.91, p=0.008)$ \\
\hline T1 & $1.78(1.21$ to $2.62, p=0.003)$ & \\
\hline T2 & $1.56(1.06$ to $2.29, p=0.003)$ & $1.83(1.18$ to $2.83, p=0.007)$ \\
\hline T3 & Ref & \\
\hline
\end{tabular}

\begin{tabular}{|c|c|c|}
\hline \multicolumn{3}{|l|}{ Tobacco } \\
\hline Non-user & Ref & Ref \\
\hline User & $1.63(1.21$ to $2.19, p=0.001)$ & $1.23(0.84$ to $1.81, p=0.293)$ \\
\hline \multicolumn{3}{|l|}{ Alcohol } \\
\hline Non-user & Ref & Ref \\
\hline User & $1.64(1.18$ to $2.29, p=0.003)$ & $1.17(0.73$ to $1.88, p=0.51)$ \\
\hline \multicolumn{3}{|c|}{ Leisure time physical activity } \\
\hline Non-sedentary & Ref & \\
\hline Sedentary & $1.09(0.75$ to $1.57, p=0.655)$ & - \\
\hline \multicolumn{3}{|c|}{ BMI classification } \\
\hline$\leq 18.50$ & Ref & Ref \\
\hline $18.51-25.00$ & $1.53(0.8$ to $2.94, p=0.201)$ & $1.42(0.74$ to $2.74, p=0.291)$ \\
\hline $25.01-30.00$ & $1.79(0.9$ to $3.55, p=0.095)$ & 1.86 (0.92 to $3.76, p=0.082)$ \\
\hline $30.01+$ & $2.48(1.15$ to $5.35, p=0.021)$ & 2.1 (0.91 to $4.86, p=0.082)$ \\
\hline \multicolumn{3}{|c|}{ Abdominal obesity } \\
\hline Non-obese & Ref & - \\
\hline Obese & $1.25(0.93$ to $1.69, p=0.134)$ & - \\
\hline \multicolumn{3}{|c|}{ BP status (2017-2018) } \\
\hline Normal & Ref & Ref \\
\hline Elevated & $2.91(2.12$ to $3.98, p<0.001)$ & $2.72(1.83$ to $4.03, p<0.001)$ \\
\hline \multicolumn{3}{|c|}{ Dysglycaemia (2017-2018) } \\
\hline Absent & Ref & - \\
\hline Present & $1.0(0.64$ to $1.56, p=1.00)$ & - \\
\hline
\end{tabular}

$\mathrm{BMI}$, body mass index; BP, blood pressure.

with those in third tertile. Among modifiable risk factors, BMI greater than $30 \mathrm{~kg} / \mathrm{m}^{2}$ increased the risk of new onset hypertension (RR 2.1; 95\% CI 0.91 to 4.86), however it was statistically not significant. Individuals who had an elevated blood pressure at baseline (or prehypertension) had a significantly increased risk of converting to hypertension on follow-up (RR 2.72; 95\% CI 1.83 to 4.03). The risk of new onset hypertension was more in individuals who were not literate (RR 1.94; 95\% CI 1.31 to 1.86) (table 2).

\section{DISCUSSION}

We found that incidence of hypertension in urban slums of central India is progressively higher with increasing age, lower Wealth Index tertiles and more in men as compared with women in each age band. Overall, about 4 new hypertensives are likely to be detected for every 100 individuals followed up in a community for a year. In addition to age and Wealth Index tertiles, we found lower education level and elevated blood pressures at baseline as significant predictors of incident hypertension. These features help us to identify vulnerable groups within the urban slum population, who are more at risk. Most concerning of these are individuals who had an elevated blood pressure (also known as prehypertension) at baseline, who are at three times greater risk of converting to new onset hypertension. This group is also numerically largest, constituting about two-fifths of the entire cohort at baseline.

While various studies have reported prevalence of hypertension in India, there are only a limited studies on its incidence. In a study conducted in 2010 from Kerala (a high non-communicable disease-burden state in India), the reported incidence of hypertension was 3.3\%. ${ }^{5}$ More recently CARRS Study from metropolitan cities of New Delhi, Chennai and Karachi reported a much higher incidence of about $8.2 \%{ }^{6}$ These variations could be a reflection of time period of the study, its setting or duration of follow-up. Various pre-2010 studies from China and Korea have reported lower incidence rates of 2.3\%, $5.2 \%$ and $5.3 \%$, respectively. ${ }^{17-19}$ However, in the same time period, incidence rates in North America and Europe were comparatively higher, ranging from $6 \%$ to $9 \%$ in various age-gender subgroups. ${ }^{20-22}$ More recent assessments in the previous decade (table 3 ) have suggested lower annual incident hypertension rates in studies from communities in Switzerland ${ }^{23}$ and Germany ${ }^{24}$ (between $2 \%$ and $3 \%$ ), but higher levels (between $8 \%$ and $12 \%$ ) in other studies from China ${ }^{25}$ and Germany. ${ }^{26}$ Such a heterogeneity indicates dynamicity in incidence rates, indicative of epidemiological transition from lower to higher hypertension prevalence. When higher proportion of individuals are classified as having hypertension, pool of at-risk individuals without hypertension shrinks, accounting for lower incidence. For instance, in a study from Germany, the annual incidence was between $8 \%$ and $9 \%$ in the first 4 years of follow-up, but reduced to $5 \%-6 \%$ in the subsequent 5 years. ${ }^{26}$ It has been observed that incidence rates are lower with longer follow-up periods. With that perspective, of the two previous studies from India, a study from Kerala with $3.3 \%$ incidence was a 7-year follow-up from 2003 to 2010, and CARRS Study with $8.2 \%$ incidence is a 2-year follow-up from 2015 to 2017. Our study from urban slums of a moderately sized city in India has an intermediate overall incidence rate of $4.45 \%$ in a median follow-up duration of 1.25 years.

Illiteracy and lower Wealth Index tertiles indicating socioeconomic position were another significant 
Table 3 Estimates and determinants of incident hypertension (HTN) in population-based studies published in the last decade

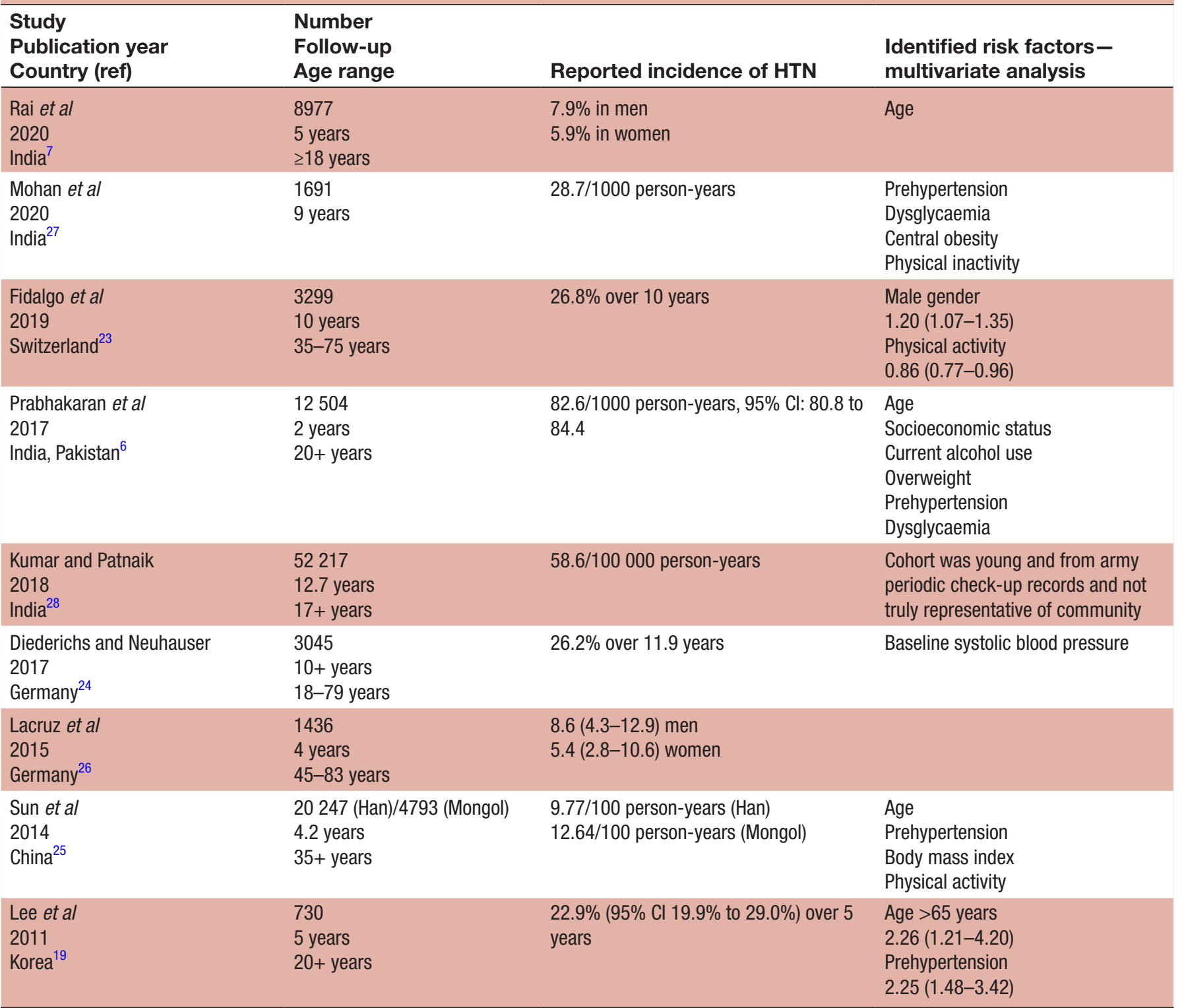

predictors of incident hypertension in our study. Smoking and alcohol consumption were also significant on univariate analysis, in our study, but these two are likely to be outcomes of illiteracy and hence intermediary in pathway to causation of hypertension. Previous studies have identified alcohol use as significant risk factor, ${ }^{6}$ and a metaanalysis of 20 cohort studies also found that any level of alcohol consumption is associated with increased risk of hypertension (RR 1.51 (95\% CI 1.30 to 1.76)) for three to four drinks per day, and 1.74 (95\% CI 1.35 to 2.24) for five or more drinks per day in men, and 1.42 (95\% CI 1.22 to 1.66$)$ for three or more drinks in women. ${ }^{9}$ Obesity, as an indicator of reduced physical activity, was significant predictor on univariate analysis in our study. These two variables have been reported to increase risk of hypertension in recent studies. ${ }^{623}$ A recent meta-analysis of 22 cohort studies has estimated that in every 10 additional metabolic equivalents of leisure time physical activity, there is reduced risk of incident hypertension by about $6 \%$ (RR 0.94 (95\% CI 0.92 to 0.96$)$ ). ${ }^{10}$

Our results from a vulnerable lower income population add to the evidence base of determinants of incident hypertension from India. We also demonstrate feasibility of establishing a cohort within the public health delivery system, driven by efforts of ASHAs who are community health workers in urban slum communities. Blood pressures at baseline as well as on follow-up were measured by ASHAs, and a comparable incidence with other similar studies validates their measurement skills. Limitation of the study is a shorter period of follow-up, however we have shown that blood pressure change is dynamic, and conversion to a hypertensive state is demonstrable within this interval. Urban slum population is prone to outward migration, as shown in attrition in cohort numbers; however, our overall CIs indicate a reasonable certainty in our point estimates. Results of our study are 
generalisable to other similar urban slum populations, who share similar built environments, socioeconomic priorities and vulnerability in terms of access to healthcare. We are limited by not being able to generalise our results to other population groups that do not share these attributes.

We believe that ours and other similar studies will be able to strengthen implementation of NPCDCS and help evaluate preventive strategies in shorter time frames. Since diagnosis of hypertension requires lifelong care, our efforts in improving preventive care can be measured in terms of annual incidence of hypertension with each passing year. Such estimates are now feasible within programmatic settings, with implementation of annual blood pressure screening in all adults.

\section{Twitter Abhijit P Pakhare @drpakhare}

Acknowledgements Investigators would like to acknowledge efforts of all community health workers (ASHAs) and their officials affiliated to urban public health system in implementing this study.

Contributors RJ conceived the study. RJ, APP and SK developed the protocol. $\mathrm{AL}$ and NS acquired data, AJ and SK supervised data acquisition, APP, AJ and RJ analysed the data and wrote the first draft. All authors critically reviewed the first draft and provided input for its revisions.

Funding This study was funded by the Indian Council of Medical Research, New Delhi as an extramural project grant (Grant-PI Dr Rajnish Joshi, IRIS-2014-0976).

Disclaimer Funders have no role in data collection, analysis and writing of the manuscript.

Competing interests None declared.

Patient consent for publication Not required.

Ethics approval Baseline and follow-up assessment protocol was approved by the Institutional Human Ethics committee of All India Institute of Medical Sciences, Bhopal (IHEC-LOP/2017/EF00045). All participants provided a written informed consent prior to baseline assessment.

Provenance and peer review Not commissioned; externally peer reviewed.

Data availability statement Data are available upon reasonable request to the corresponding author.

Open access This is an open access article distributed in accordance with the Creative Commons Attribution Non Commercial (CC BY-NC 4.0) license, which permits others to distribute, remix, adapt, build upon this work non-commercially, and license their derivative works on different terms, provided the original work is properly cited, appropriate credit is given, any changes made indicated, and the use is non-commercial. See: http://creativecommons.org/licenses/by-nc/4.0/.

\section{ORCID iDs}

Abhijit P Pakhare http://orcid.org/0000-0003-2897-4141

Neelesh Shrivastava http://orcid.org/0000-0001-5270-6206

Rajnish Joshi http://orcid.org/0000-0002-4702-0522

\section{REFERENCES}

1 Anchala R, Kannuri NK, Pant H, et al. Hypertension in India: a systematic review and meta-analysis of prevalence, awareness, and control of hypertension. $J$ Hypertens 2014;32:1170-7.

2 Kokane AM, Joshi R, Kotnis A, et al. Descriptive profile of risk factors for cardiovascular diseases using WHO step wise approach in Madhya Pradesh. PeerJ 2020;8:e9568.

3 Gupta R, Gaur K, S Ram CV. Emerging trends in hypertension epidemiology in India. J Hum Hypertens 2019;33:575-87.

4 MoHFW. National programme for prevention and control of cancer, diabetes, cardiovascular diseases and stroke (NPCDCS). Ministry of Health and Family Welfare, Government of India, 2019. Available: https://main.mohfw.gov.in/Major-Programmes/non-communicablediseases-injury-trauma/Non-Communicable-Disease-II/National-
Programme-for-Prevention-and-Control-of-Cancer-DiabetesCardiovascular-diseases-and-Stroke-NPCDCS [Accessed 6 Jan 2021].

5 Sathish T, Kannan S, Sarma PS, et al. Incidence of hypertension and its risk factors in rural Kerala, India: a community-based cohort study. Public Health 2012;126:25-32.

6 Prabhakaran D, Jeemon P, Ghosh S, et al. Prevalence and incidence of hypertension: results from a representative cohort of over 16,000 adults in three cities of South Asia. Indian Heart J 2017;69:434-41.

7 Rai RK, Kumar C, Singh PK, et al. Incidence of prehypertension and hypertension in rural India, 2012-2018: a Sex-Stratified populationbased prospective cohort study. Am J Hypertens 2020;33:552-62.

8 Gupta R. Convergence in urban-rural prevalence of hypertension in India. J Hum Hypertens 2016;30:79-82.

9 Roerecke M, Tobe SW, Kaczorowski J, et al. Sex-Specific associations between alcohol consumption and incidence of hypertension: a systematic review and meta-analysis of cohort studies. J Am Heart Assoc 2018;7. doi:10.1161/JAHA.117.008202

10 Liu X, Zhang D, Liu Y, et al. Dose-response association between physical activity and incident hypertension: a systematic review and meta-analysis of cohort studies. Hypertension 2017;69:813-20.

11 Nadar SK. Spotlight on hypertension in the Indian subcontinent. $J$ Hum Hypertens 2019;33:559-61.

12 Pakhare AP, Joshi A, Khadanga S, et al. Feasibility of community health worker based cardiovascular risk reduction strategies in urban slums of Bhopal: rationale and design of community based study. medRxiv 2020.

13 R Core Team. R: A Language and Environment for Statistical Computing. Vienna, Austria: : R Foundation for Statistical Computing, 2019. Available: https://www.R-project.org/

14 Dorai-Raj S. binom: binomial confidence intervals for several Parameterizations, 2014. Available: https://CRAN.R-project.org/ package=binom [Accessed 19 Oct 2020].

15 et alSjoberg DD, Curry M, Hannum M. gtsummary: Presentationready data summary and analytic result tables, 2020. Available: https://CRAN.R-project.org/package=gtsummary [Accessed 17 Oct 2020].

16 Donoghoe MW, Marschner IC. logbin : An $R$ Package for Relative Risk Regression Using the Log-Binomial Model. J Stat Softw 2018;86:1-22.

17 Wu X, Huang Z, Stamler J, et al. Changes in average blood pressure and incidence of high blood pressure 1983-1984 to 1987-1988 in four population cohorts in the people's Republic of China. The PRCUSA cardiovascular and cardiopulmonary epidemiology Research Group. J Hypertens 1996;14:1267-74.

18 Gu D, Wildman RP, Wu X, et al. Incidence and predictors of hypertension over 8 years among Chinese men and women. $J$ Hypertens 2007;25:517-23.

19 Lee JH, Yang DH, Park HS, et al. Incidence of hypertension in Korea: 5-year follow-up study. J Korean Med Sci 2011;26:1286-92.

20 Dannenberg AL, Garrison RJ, Kannel WB. Incidence of hypertension in the Framingham study. Am J Public Health 1988;78:676-9.

21 Diez Roux AV, Chambless L, Merkin SS, et al. Socioeconomic disadvantage and change in blood pressure associated with aging. Circulation 2002;106:703-10.

22 Rywik SL, Williams OD, Pajak A, et al. Incidence and correlates of hypertension in the Atherosclerosis Risk in Communities (ARIC) study and the monitoring trends and determinants of cardiovascular disease (POL-MONICA) project. J Hypertens 2000;18:999-1006.

23 Fidalgo ASQ, Vollenweider P, Marques-Vidal P. Ten-year incidence of hypertension in a Swiss population-based sample incidence of hypertension in Switzerland. J Hum Hypertens 2019;33:115-22.

24 Diederichs $\mathrm{C}$, Neuhauser $\mathrm{H}$. The incidence of hypertension and its risk factors in the German adult population: results from the German National health interview and examination survey 1998 and the German health interview and examination survey for adults 20082011. J Hypertens 2017;35:250-8.

25 Sun Z, Zheng L, Zhang X, et al. Ethnic differences in the incidence of hypertension among rural Chinese adults: results from Liaoning Province. PLoS One 2014;9:e86867.

26 Lacruz ME, Kluttig A, Hartwig S, et al. Prevalence and incidence of hypertension in the general adult population: results of the CARLACohort study. Medicine 2015;94:e952.

27 Mohan V, Anjana RM, Unnikrishnan R, et al. Incidence of hypertension among Asian Indians: 10 year follow up of the Chennai Urban Rural Epidemiology Study (CURES-153). J Diabetes Complications 2020;34:107652.

28 Kumar KVSH, Patnaik SK. Incidence of essential hypertension in young adult males followed for over two decades. Indian Heart $J$ 2018;70:S1-3. 